\title{
MARIA GRASIELA TEIXEIRA BARROSO: DESENVOLVIMENTO PROFISSIONAL NA ENFERMAGEM CEARENSE
}

- MARIZA DA COSTA PEREIRA

https://orcid.org/0000-0002-0466-8652

Universidade Estadual do Ceará

SILVIA MARIA NÓBREGA-THERRIEN

http://orcid.org/0000-0002-9660-8314

Universidade Estadual do Ceará

ANDRÉA DA COSTA SILVA

https://orcid.org/0000-0001-6207-9306

Universidade Estadual do Ceará

RESUMO O texto versa sobre a trajetória de vida pessoal e profissional de Maria Grasiela Teixeira Barroso, evidenciando sua implicação constante e dedicada à formação e ao ensino do profissional enfermeiro. Constitui recorte de uma pesquisa maior de uma das autoras, que teve por objetivo registrar a história de vida pessoal e profissional da Professora móvel do ensaio. Conforma uma investigação com abordagem qualitativa, cuja metodologia utilizada foi do tipo História Oral. A coleta de dados se deu mediante a técnica da história oral temática híbrida, que combina as fontes orais com uma documentação densa paralela, escrita ou iconográfica. Com base nas análises, constatou-se que Grasiela Barroso teve intensiva participação na história da Enfermagem no Ceará, visto que trabalhou incansavelmente pelo crescimento desse oficio-arte, preocupando-se com o ensino dos novos enfermeiros, dedicando-se a constituir saberes e modernizar as referidas práticas, com âncora em concepções e promoção da saúde. Conclui-se que se faz necessário registrar a história e a memória de profissionais que consolidaram as bases desse relevante ofício, preservando e enaltecendo os feitos e ações dessas personalidades.

Palavras-chave: Biografia. História da Enfermagem. Práticas de Ensino. 


\section{MARIA GRASIELA TEIXEIRA BARROSO: PROFESSIONAL DEVELOPMENT IN CEARENCE NURSING}

The text deals about the personal and professional life trajectory of Maria Grasiela Teixeira Barroso, evidencing its constant and dedicated implication to the formation and teaching of the professional nurse. It is a clipping of a larger research by one of the authors, which aimed to record the personal and professional life story from the mobile essay teacher. It conforms an investigation with qualitative approach whose methodology was of the Oral History type. Data collection took place through the technique of hybrid thematic oral history, that combines oral sources with dense parallel documentation, written or iconographic. Based on the analyzes, Grasiela Barroso had an intensive participation in the history of nursing in Ceará, since she worked tirelessly for the growth of this craft, worrying about the teaching of new nurses, dedicated to building knowledge and modernize these practices with anchor in conceptions and health promotion. It is concluded that it is necessary to record the history and memory of professionals that consolidated the foundations of this relevant craft, preserving and praising the deeds and actions of these personalities.

Keywords: Biography. Nursing History. Teaching Practices.

\section{RESUMEN}

\section{MARIA GRASIELA TEIXEIRA BARROSO: DESARROLLO PROFESIONAL EN ENFERMERÍA CEARENSE}

Trata sobre la trayectoria personal y profesional de Maria Grasiela Teixeira Barroso, destacando su implicación constante y dedicada a la formación y enseñanza de la enfermera profesional. Constituye recorte de una investigación más grande realizada por uno de los autores, que tuvo como objetivo registrar la historia de la vida personal y profesional de la profesora motivo del ensayo. Conforma una investigación con enfoque cualitativo cuya metodología fue del tipo de Historia Oral. Los datos fueron recolectados por técnica de historia oral temática híbrida, que combina fuentes orales con documentación paralela densa, escrita o iconográfica. Con base en los análisis, se constató que Grasiela Barroso tuvo participación intensa en la historia de la enfermería en Ceará, trabajó incansablemente para el crecimiento de este oficio-arte, preocupándose por la enseñanza de nuevas enfermeras, dedicada a constituir conocimiento y modernizar las prácticas referidas con anclajes concepciones y promoción de la salud. Se concluye que es necesario registrar la historia y la memoria de los profesionales que consolidaron los fundamentos de 
la profesión de este personaje relevante, preservando y ensalzando los hechos y acciones de estas personalidades.

Palabras clave: Biografia. Historia de enfermería. Prácticas de enseñanza.

\section{Introdução}

Este texto focaliza a história de Maria Grasiela Teixeira Barroso (1926-2011), com o objetivo de registrar a história de vida pessoal e profissional dessa Enfermeira e professora, que, particularmente, atuou e contribuiu na formação da Enfermagem do Estado do Ceará. Sendo ela enfermeira por formação, conquistou o título de Professor Emérito ${ }^{1}$ da Universidade Federal do Ceará - UFC (1994), tendo dedicado meio século de sua vida à Enfermagem. Esta investigação é o recorte de uma pesquisa maior de uma das autoras.

A carreira profissional da Pioneira ${ }^{2}$, Grasiela Barroso, começou cedo. Registrou meio século de dedicação à Enfermagem, tempo durante o qual a Professora nascida no Município de Palmácia militou em distintas dimensões na seara profissional, entre elas, as destacadas por Sanna (2007), conformadas em assistir, administrar, ensinar e pesquisar, definidas como processos de trabalho do profissional de Enfermagem.

A história da Enfermagem profissional no Ceará é constituída pela narrativa de vários homens e mulheres que contribuíram com seus pensamentos e ações no cotidiano do exercício laboral, porém, e, a não ser em in-

1 Professor Emérito é o título honorífico atribuído ao docente, aposentado dessa Universidade, que se haja distinguido com ações relevantes e dedicação integral ao ensino, pesquisa ou extensão no curso de sua carreira, a ser proposto pelo Conselho da Unidade Acadêmica, mediante exposições de motivos e memorial. (UFC, s.d.) O título foi outorgado pelo Magnífico Reitor, Prof. Antônio de Albuquerque Sousa Filho, deliberado por unanimidade do Conselho Universitário em 1994 da UFC.

2 Recorremos a essa palavra para definir a Grasiela, visto que, com base no dicionário Aurélio - Pioneira: é aquela que abre caminho, aquele que é precursor. Desse modo, a enfermeira Grasiela fez-se pioneira por criar e fundar o curso de Enfermagem da UFC. formações esparsas, inexistem estudos sobre essas personagens da história do Ensino da Enfermagem no Estado.

Mendes (2013) aponta que um dos fatores das lacunas dessa história é a falta de documentos e estudos sobre a história da Enfermagem no Ceará, constatada concretamente nos vários eventos realizados da categoria profissional. Outro fator constitui a falta de pesquisadores na temática. Na busca de preencher as lacunas da história da Enfermagem no Estado, este escrito propõe-se ampliar as pesquisas de precursores que fizeram história e contribuíram para a formação profissional da Enfermagem.

Isto posto, para atingir nosso objetivo, este artigo se organiza em seções, partindo da introdução, que exprime a temática do estudo, seguindo o caminho trilhado em busca dos dados da pesquisa. Na sequência, narramos os episódios iniciais da infância, escolarização e contexto familiar da Pioneira. Depois, na vida adulta, cuidamos de descrever os passos dados na profissão enfermeira/docente, seus cuidados com a formação de enfermeiros, o desenvolvimento com a liderança e empenho no âmbito da pesquisa ordenada, em busca de tornar científico o oficio profissional sob exame. Concluímos o texto com as devidas considerações sobre o percurso trilhado e respondemos ao objetivo do ensaio.

\section{Caminho Metodológico Trilhado ao biografar Grasiela}

Para o alcance do objetivo, a pesquisa amparou-se na abordagem qualitativa, em que recorremos à História Oral como metodologia. 
Nessa perspectiva, utilizamos as lembranças e memórias dos sujeitos próximos a Grasiela Barroso, visto que, "[...] a memória é a chave que permite ao pesquisador apropriar-se do acontecimento pela via interpretativa de quem o viveu e que, ao narrar, reconstrói o vivido à sua maneira e torna o fato imortal". (ESQUINSANI, 2012, p. 221). Ferreira e Amado (2006) fazem uma reflexão a respeito do uso da história oral, expressando a riqueza e as dificuldades, mostrando que a recorrência às vertentes orais permite uma imersão na memória das pessoas, possibilitando visões subjetivas e singulares para a história contada.

De tal maneira, o traçado da história de uma pessoa inclui um conjunto de intenções e finalidades ao pesquisador, de maneira a retratar o modo de vida do biografado, as experiências vividas, a prática desenvolvida, as influências, os desafios encontrados, a superação deles, e, ainda, relatar, momentos históricos que implicaram mudanças significativas para a sociedade.

Sanna (2011) evidencia a ideia de que a Enfermagem é uma das áreas que têm interesses em biografar suas personagens, delas fazendo exemplos, valorizando o trabalho e exaltando as experiências na Enfermagem. Padilha et alii (2011) complementam nesse sentido, assinalando que

As biografias ou trajetórias de vida das enfermeiras têm sido utilizadas na educação de enfermagem com várias finalidades - ressaltar o desenvolvimento de uma área profissional específica; orientar a criação de escolas de enfermagem e associações profissionais; criar teorias de enfermagem; investigar os avanços sociais e políticos da profissão. (P. 248).

É sabido que as personagens marcantes biografadas deixaram sinais, principalmente pelo fato de terem contribuído para a implantação das primeiras escolas de Enfermagem, além de haverem se dedicado ao estudo sobre as origens e o desenvolvimento desse oficio. A esse respeito, Barreira (1999) assinala que, na qualidade de sujeitos históricos, estas pioneiras lutaram para estabelecer uma identidade profissional coletiva, revelando outra perspectiva sobre e para a profissão.

Cada história dessas personagens constituiu um mosaico forte que ajudou a instituir uma profissão e sua oficialização na realidade brasileira. Foram enfermeiras e enfermeiros que, ao seu modo e ante as condições estruturais de sua época, estabeleceram o diferencial na formação desses profissionais, sob os auspícios da Ciência e da Arte - conforme se expressa ser a Enfermagem.

Desse modo, por intermédio da História Oral, nos debruçamos nos registros de uma personagem assinalada para a formação em Enfermagem no Estado do Ceará, que foi Maria Grasiela Teixeira Barroso. Ancoramo-nos, sobretudo, em narrativas oriundas da memória dos sujeitos, que retratam a experiência de vida de uma pessoa cuja trajetória foi significativa para a compreensão de eventos, períodos, práticas culturais e históricas, registrada e analisada, esclarecendo percursos individuais e processos coletivos (MEIHY; HOLANDA, 2013), notadamente na senda da Enfermagem e no terreno educacional.

Conforme adiantamos, para a recolha dos indicadores, optamos pela técnica histórica oral - temática híbrida, que combina fontes orais e documentação escrita ou iconográfica, realizando o diálogo de fontes. A realização de entrevistas com pessoas que se aproximem do conhecimento do objeto de estudo permitiu a elaboração e reconstituição da história por meio dos relatos individuais (OLIVEIRA et alii., 2013).

Os entrevistados, por via da oralidade, relataram as memórias acerca da trajetória de vida pessoal e profissional da Pioneira. Os discursos foram captados pelo instrumento de coleta es- 
colhido, gravados, o que permitiu maior riqueza na captação do registro do áudio, tornando a fala fidedigna. Na sequência, as fontes orais foram transcritas e textualizadas. Além das entrevistas, recorremos a vertentes documentais - artigos científicos, currículo lattes e livros e capítulos que tratam da vida de Grasiela.

As entrevistas, neste estudo, foram temáticas e realizadas com três pessoas pinçadas intencionalmente, porquanto deveria a escoIha recair naquelas que tivessem vivido e participado da vida pessoal e/ou profissional da Enfermeira sob exame histórico, e que guardassem interesse em participar do ensaio, visto que a pesquisa é in memoriam, pois Grasiela Barroso é falecida ${ }^{3}$.

A primeira pessoa a aceitar o convite foi Maria Dalva Santos Alves, grande amiga e companheira de trabalho de Grasiela, por quase 50 anos. Maria Dalva escreveu um capítulo de livro, em conjunto com outros autores, sobre Grasiela Barroso e sua dedicação à Enfermagem. Maria Dalva aportou contribuições para reconstituir a temática da vida profissional, além de tornar disponiveis diversos arquivos sobre a Mestra estudada nesta relação histórica.

O segundo entrevistado foi Vicente Teixeira Barroso, um dos filhos de Grasiela, que prontamente decidiu ajudar na pesquisa, concedendo entrevista e respondendo a perguntas acerca da vida pessoal de sua celebrada Mãe.

A terceira entrevistada foi Neiva Francenely Cunha Vieira, ex-aluna de Grasiela na graduação. Posteriormente, Neiva se inseriu como professora no grupo de docentes da UFC e tinha Grasiela como amiga, coordenadora. Ambas, também, foram docentes colaboradoras de uma mesma disciplina para a turma do Mestrado. A entrevistada colaborou para as informações acerca da vida, principalmente aca-

3 Grasiela Barroso foi a óbito no dia 13 de maio de 2011, aos 85 anos. dêmica, da trajetória de Grasiela no Curso de Enfermagem da UFC.

No corpo do texto, as falas dos entrevistados são identificadas pelo último sobrenome - Alves, Barroso e Vieira - seguidos da data de realização dos encontros, em 2017. Os instrumentos foram aplicados no local e no horário escolhidos pelos entrevistados, após a assinatura do Termo de Consentimento Livre e Esclarecido (TCLE), onde foram respeitadas normas de rigor ético em pesquisa com pessoas humanas - in anima nobili - conforme as Resoluções números 466/2012 e 510/2016.

\section{Episódios iniciais da história de vida de Maria Grasiela Teixeira}

\section{Barroso}

Grasiela Barroso nasceu aos 6 de maio de 1926, na cidade serrana de Palmácia, no Estado do Ceará, que, então, pertencia ao Município de Maranguape.Quarta filha de Rita Stela Nepomuceno Teixeira e João Teixeira Joca, proveio de uma família de oito filhos, que vem na seguinte ordem decrescente:Rita Yolanda Nepomuceno Teixeira, João Teixeira Filho, Madalena Nepomuceno Teixeira, Maria Grasiela Nepomuceno Teixeira, Zélia Nepomuceno Teixeira, José Luciano Teixeira, Reginaldo Nepomuceno Teixeira e Marcos Stênio Teixeira. Foi a quarta de oito irmãos e irmãs.

Filha de agricultores, donos de duas propriedades agrícolas, uma na cidade de Palmácia e outra em Maranguape (Amanari). Sua infância foi marcada pelo espírito familiar, vivendo no sertão durante o inverno e na serra quando verão. Sua educação primária teve como marca o ensino domiciliar, com uma professora contratada para ensinar e acompanhar Grasiela e seus irmãos (FREIRE, 20024).

4 Artigo periódico publicado na Revista Rene em 2002, por Lidiane Dias Freire, tendo como título Grasiela um marco nos 25 anos do curso de enfermagem da 
Durante esse período no Brasil, começo do século XX, se dava o início da democratização do ensino e da escola pública. Um dos maiores desafios da época era o analfabetismo. 0 processo acontecia lentamente, de sistematização e garantia de direitos fundamentais, em decorrência de várias dificuldades: falta de prédios escolares, ausência da formação de professores e de investimentos em material didático (FREITAS; BICCAS, 2009).

Em tais circunstâncias, os pais de Grasiela Barroso possibilitaram o ensino de primeiras letras aos filhos, em casa. Pelo fato de não morarem na Capital, o acesso a escolas tornavase ainda mais dificil. Posteriormente, a família foi residir em Baturité, em 1943, quando Grasiela deu continuidade aos estudos no Colégio Nossa Senhora Auxiliadora, recebendo, assim, uma educação formal sob a perspectiva religiosa, seguindo os padrões da época. Concluiu o 2 o grau em Fortaleza, garantindo o diploma de professora primária (FREIRE, 2002). Durante sua adolescência, Grasiela Barroso dedicavase aos estudos e às atividades da religião, já que sua formação escolar acontecia em regime de internato. Apesar disso, "[...] ela gostava de passear com as irmãs e primas, de sair para conversar, gostava de reunir, de aglomerar", relatou o filho de Grasiela (BARROSO, 16/10/2017).

Casou-se, em julho de 1948 com o Dr. Sérvulo Mendes Barroso, graduado em Odontologia no ano de 1947. Órfão de pai muito cedo, Sérvulo enfrentou dificuldades financeiras, junto com sua mãe e irmã. Prestou exame vestibular para Odontologia e ingressou no curso no ano de 1945. Anterior a isso, Sérvulo foi combatente, convocado para o serviço militar durante a 2a a Guerra Mundial, quando serviu nas Bases Aéreas de Fortaleza e Recife (BARROSO, 16/10/2017).

FFOE - UFC, que aborda passagens da vida familiar e profissional de Grasiela, descrevendo fatos e ações que apontam o reconhecimento do seu trabalho.
Do matrimônio foram gerados três filhos: Vicente, Maria Eugênia e Rômulo, graduados, respectivamente, em Engenharia Civil, Gastronomia e Administração de Empresas. Dr. Sérvulo configurou um dos principais incentivos e inspiração para a escolha da profissão de Grasiela Barroso. Por muitos anos, ela o auxiliava durante as cirurgias, pois

[...] trabalhou com meu pai durante anos, ela sempre ia pra cirurgia com meu pai, [...] operava muito com o papai na Casa de Saúde São Raimundo, no Cura d'Ars, [...] papai foi cirurgião da Santa Casa por 15 anos, e ela sempre acompanhava ele, eles eram muito amigos (BARROSO, 16/10/2017).

A trajetória acadêmica e profissional da professora e doutora Grasiela Barroso teve um grande destaque e mereceu reconhecimento. Veremos nas seções seguintes os marcos e ações de sua atuação.

\section{Percurso de formação e inserção}

\section{na carreira do magistério}

O locus para a formação inicial de Grasiela Barroso foi a Escola de Enfermagem São Vicente de Paulo - EESVP, na qual iniciou seu curso no ano de 1956. Na época, a Escola encontrava-se récem -agregada a então Universidade do Ceará, criada em 1954. Grasiela ingressou aos 30 anos na Enfermagem, era casada e tinha seu filho mais velho, Vicente. Durante a graduação, engravidou, pela segunda vez, de Maria Eugênia, no entanto, cumpriu sua carga horária, escalas, estágios e tarefas acadêmicas (ALVES et alii., 2016).

Alves et alii. (2016) expressaram que Grasiela, enquanto foi aluna do Curso de Enfermagem “[...] se destacava como aluna exemplar, apaixonada e sempre compromissada. Não the agradava parecer importante, demonstrandose sempre humilde e recatada". (P. 89). Desde a vida acadêmica, demonstrava dedicar-se com afinco à profissão. 
Concluiu a graduação em Enfermagem, tendo a celebração dos concludentes da turma acontecido em 1959, em Fortaleza. Realizou-se uma missa em ação de graças, celebrada pelo Bispo - Auxiliar da Arquidiocese de Fortaleza, Dom Expedito Eduardo de Oliveira, na capela do Patronato Nossa Senhora Auxiliadora, sequenciada pela solenidade da colação de grau, no Theatro José de Alencar. 0 ato solene teve a cerimônia das lâmpadas, e a dama da turma foi a aluna Alice Nogueira do Nascimento, passando nas mãos das neodiplomadas o símbolo mundial da Enfermagem - a lâmpada de Florence Nightingale.

0 processo formativo inicial possibilitado pela EESVP envolveu Grasiela tão logo nos saberes da docência, no mesmo ano do término de sua graduação. Ela integrou, de 1959 a 1971, o quadro de docentes da EESVP, lecionando as disciplinas Enfermagem em Saúde Pública, Enfermagem Pediátrica, Enfermagem em Clínica Médica, Dietética Infantil, Economia Hospitalar, Saneamento, Problemática de Enfermagem e Ética Profissional (FREIRE, 2002).

Desde o início da carreira docente, Grasiela Barroso direcionava o aluno para a aprendizagem-científica. Acreditava que o estudante era responsável pelo próprio aprendizado e este se ancorava em um saber científico. Apoiava-se nos estudos de Carl Rogers ${ }^{5}$ na proposta de aprendizagem centrada no aluno (VIEIRA, 16/10/2017). Ponderava na ideia de que, "O aluno deveria ser colocado, inicialmente, em situações de ensino-aprendizagem com grupos de vizinhanças, desenvolvendo ações que cresceriam em complexidade à proporção que fossem cursando disciplinas". (BARROSO; SILVA; VARELA, 2006, p. 150). Essas foram as palavras da Pioneira, em um discurso escri-

5 Carl Rogers (1902-1987), psicólogo estadunidense, cuja “[...] proposta de atuação pedagógica coloca o aluno no centro do processo de aprendizagem, produzindo um conhecimento baseado na experiência significativa e tendo na figura do professor o suporte necessário e um facilitador deste processo". (ESCÁRIO, 2014, p. 83). to em comemoração aos 25 anos do curso de Enfermagem da UFC. Para a então Professora, a aprendizagem é um processo de amadurecimento de uma prática.

Em 1975, Grasiela Barroso integrou o corpo docente do Departamento de Enfermagem da Universidade Federal do Ceará, contratada inicialmente como auxiliar de ensino, com o objetivo de estruturar o curso de Enfermagem da UFC, com vigência desde primeiro de setembro de 1975 (BARROSO; COSTA; VARELA, 1992).

No currículo lattes de Grasiela, encontramos, no item Atuação Profissional, algumas das disciplinas que a Enfermeira ministrou no recorte temporal de 1982 a 1999, isso após sua atuação como coordenadora do curso de Enfermagem, de março de 1976 a junho de 1982, na UFC. A professora Grasiela atuou nos níveis de graduação e pós-graduação stricto e lato sensu, ministrando disciplinas como: Estágio, Didática aplicada à Enfermagem, Supervisão e Treinamento do Pessoal de Enfermagem, Exercício em Enfermagem, Legislação do Ensino e do Exercício de Enfermagem, Tecnologia Aplicada à Administração, Administração em Serviços de Enfermagem em Saúde Pública, Tendências de Enfermagem, Produção Científica de Eventos em Enfermagem; Estudo Crítico dos Programas de Ensino de Enfermagem, Metodologia do Ensino de Enfermagem - e diversas disciplinas de pesquisa.

A conduta de Grasiela como professora tinha intensa inspiração nos escritos do educador Paulo Freire. O processo educativo, para ela, deveria ser feito de uma maneira em que houvesse a formação de profissionais éticos, críticos e bem preparados, fazendo uso do diálogo e da problematização, respeitando o contexto social dos alunos.

Em um de seus escritos, Grasiela e uma de suas orientandas de doutorado, em coautoria, analisaram as contribuições de Paulo Freire para a prática e educação crítica na Enferma- 
gem, inventariando os conceitos trabalhados por Freire para a educação dos enfermeiros. Miranda e Barroso (2004) exprimem a reflexão conforme a qual

[...] o pensamento de Freire tem colaborado de forma significativa na construção de uma educação reflexiva na enfermagem, incorporando uma educação crítica e problematizadora, tendo como leitmotiv o diálogo com seus educandos; compreendendo o que é e para que serve a educação, indo de encontro à proposta pedagógica ainda hegemônica do monólogo, batendo de frente com aqueles conteúdos prontos e preestabelecidos. (P. 634).

As ideias do educador pernambucano Paulo Freire com relação à prática do ensino foram seguidas pela Professora Grasiela, na observação do compromisso com uma educação que liberte, desenvolvendo a cidadania, a solidariedade e o respeito. 0 caminho para se chegar a essa proposta pedagógica libertadora é desafiador, requer ousadia. Mediante o discurso de uma das entrevistadas, percebemos que Grasiela fazia uso constante do diálogo, da problematização e da chamada metodologia ativa, que consiste em situar diretamente os alunos para serem condutores do próprio aprendizado, ideais defendidos pelo educador Paulo Freire.

Ela acreditava no aluno, na sua autonomia, sua independência, a sua emancipação. Ela ensinava a pescar e não dava o peixe, entendeu? Problematizava muito. "Reflita, não me dê à resposta agora não, procure se informar". Então, ela exercitava muito a estratégia de fazer com que o aluno fosse autônomo, independente, emancipado, livre, né, para buscar os próprios caminhos. (VIEIRA, 16/10/2017).

A entrevistada, ex-aluna de Grasiela, revela algumas das estratégias de ensino usadas por ela, conforme se recorda: “[...] estudos em grupos, seminários, estudo dirigido de textos, ela tinha essa coisa de fazer com que o aluno fosse autônomo, independente, buscasse o aprendizado" (VIEIRA, 16/10/2017), pensando na formação de um sujeito ativo, redirecionando o foco do processo de ensino para o próprio aluno, em que este seria responsável pelos seus estudos, pois o acadêmico não ia simplesmente assistir às aulas, mas, também, desta participava ativamente.

Nesse intento, de formar um escolar ativo, a Professora Grasiela implantou o Programa Especial de Treinamento (PET), em 1988, modalidade de ensino tutorial que tem como objetivo possibilitar um espaço de trabalho em grupo, vivenciando a autonomia e a ética na vida acadêmica e profissional. Os bolsistas do Programa colaboram no ensino, fazendo mediações entre os estudantes e professores, bem como proporcionam experiências de reflexão crítica (BARROSO; SILVA; VARELA, 2006).

Sua posição como professora era de um bom relacionamento com seus alunos, pois sondava as dificuldades e o contexto da realidade social de seus educandos, como comenta uma das entrevistadas: "Teve muitas orientandas desde a Iniciação Científica até o Doutorado. Tinha como filhas. Recebia na sua casa. Assinava muitas revistas de Enfermagem para atender suas alunas e orientandas, assim como professores de diferentes universidades". (ALVES, 08/10/2017). Demonstrava, pois, o papel da afetividade nesta relação entre docente e escolar, bem como expressava o compromisso com a formação dos seus enfermeiros e enfermeiras.

Assim expresso, é relevante asseverar o quanto Grasiela Barroso se fez paradigma para as gerações atuais e futuras, na busca por uma carreira que se preocupasse com o seu reconhecimento, concedendo à Enfermagem motivos para lutar pelo que acredita. Sempre demandava por uma profissionalização com o status que esta merecia e que lhe era concedido pelo mérito de atuação e conduta ética e competência. 
Protagonista na criação do curso de Enfermagem da Universidade Federal do Ceará - exercendo sua capacidade de liderança

0 acelerado desenvolvimento de alguns países exige, dos profissionais de todas as áreas, diversas competências - como compromisso, honestidade, autodisciplina, dentre outras - do que se destaca a liderança (SOUSA; BARROSO, 2009). A habilidade do líder pode se manifestar em qualquer pessoa, desde que esta guarde um propósito, desenvolvendo ações para alcançar o alvo e influenciando a equipe para atingir o objetivo.

[...] a enfermeira tende a desenvolver, quase que de forma inevitável, habilidades de liderança, principalmente em virtude das tarefas que the são exigidas. É necessário que a enfermeira desempenhe, seja em instituições hospitalares ou em atividades de saúde comunitária, o papel de líder, uma vez que está diretamente envolvida com análise crítica, identificação de problemas, tomada de decisões, planejamento e implementação de cuidados, alocação de outros profissionais da equipe de enfermagem e motivação dos profissionais da equipe de saúde, por exemplo. (SOUSA; BARROSO, 2009, p. 182).

Nesta perspectiva, a competência de liderar, em sua função gerencial, está imbricada aos misteres da Enfermagem, porquanto, em equipe, líderes e liderados militam em prol do sucesso no âmbito assistencial, motivando-se para o cuidado de si e do outro. Sousa e Barroso (2009) expressam a ideia de que existem dois modos de liderar, um por meio do poder e outro por via da autoridade. 0 primeiro - depreende-se - prejudica a relação de ambos os membros, ao passo que o seguinte incentiva a boa vontade dos envolvidos, prosperando numa interação dialógica, sem perder o foco no cuidado.

Ao prosseguir com esse modelo, Grasiela Barroso teve a oportunidade de liderar em di- versos espaços. Por meio da base de informações do Sistema de Currículo lattes, notamos terem sido diversos cargos. Após ingressar, no ano de 1964, como funcionária pública na Secretaria de Saúde do Estado do Ceará, Grasiela Barroso atuou em posições de administração e direção, como Chefe da Seção de Enfermagem (1966-1967); Superintendente do Serviço de Enfermagem (1965-1967); Membro da Diretoria do Conselho Regional (1974-1974) e Chefe do Serviço do Centro de Treinamento da Divisão de Treinamento do Departamento Técnico de Saúde (1971-1975). Como relembra o engenheiro Vicente Teixeira Barroso, “[...] logo notou se a sua liderança natural e ingressou na Secretaria de Saúde, na qual exerceu diversos cargos de chefia, e em destaque especial a Fiscalização do exercício da Profissão, e o famoso Centro de Treinamento". (16/10/2017).

Grasiela Barroso é havida, historicamente, como a primeira enfermeira a desenvolver atividades no Serviço de Fiscalização do Exercício Profissional (1964-1975), antes preenchido por profissionais de outras categorias. Tal setor estrutura e normatiza a função, desenvolvendo estratégias motivadoras para o cumprimento da lei (FREIRE, 2002). No múnus do lugar assumido no Centro de Treinamento da Secretaria de Saúde do Estado do Ceará, Grasiela operou com o desenvolvimento de recursos humanos. Uma das entrevistadas que trabalhou com ela se recorda de que observava a maneira de Grasiela administrar, com autoridade e sem autoritarismo, a educação continuada do Estado.

Outra função digna de destaque, trazendo o título dessa seção, foi a Coordenação do Curso de Enfermagem da UFC, de 1975 a 1982. Muito mais do que coordenar, Grasiela ajudou a estruturar o Curso. Anteriormente, em 1970, foi instada pelo reitor Fernando Leite para auxiliar na implantação do curso, porém declinou do convite, visto que o curso seria estruturado 
com o de Medicina, e seguiria um modelo curricular centrado na pessoa doente no hospital (FREIRE, 2002). Este fato é apontado como de relevo para a trajetória de Grasiela Barroso, ao perguntarmos à Professora Doutora Maria Dalva dos Santos Alves a respeito de algum fato/ episódio marcante em relação à trajetória da Pioneira como gestora. Consoante a entrevistada respondeu, Grasiela

Somente aceitou o convite para criar o Curso de Graduação em Enfermagem da UFC quando foi aceito o projeto proposto por ela e não o que quiseram the impor. (ALVES, 08/10/2017).

[...] o curso de enfermagem era pra ser dentro do hospital universitário, e ela não queria, porque a visão da Grasiela era que a enfermagem tinha que está fora do hospital. O curso tinha que nascer com o enfoque preventivista, e não com o enfoque voltado para a doença, mas com o enfoque voltado para a promoção da saúde. [...] ela não aceitava, que naquela época, o curso tivesse esse enfoque de olhar o indivíduo doente, mas sim um indivíduo sadio e promover a saúde desse indivíduo, [...] nós éramos promotores de cuidado da saúde, e não com enfoque na doença. (VIEIRA, 08/10/2017).

O segundo aceno para coordenar o planejamento/implantação do Curso veio do reitor Pedro Teixeira Barroso, em 1975. A proposta, dessa vez, tinha como eixos a promoção da saúde e a prevenção de doenças, bem como a assistência direcionada ao cuidado integral de saúde, buscando compreender o processo saúde-doença do ser humano, respeitando o seu contexto de vida.

Como em tudo o que se propunha fazer, Grasiela exercia os cargos administrativos com dedicação, compromisso, responsabilidade e ética. Expressamos, na sequência, excertos das falas que revelam sobre a vocação da Pioneira para os atos de gerenciar, na óptica das entrevistadas.

Acredito que Grasiela já nasceu líder. Era moderadora na sua labuta como enfermeira, sen- do ela gestora, consultora, assessora. (ALVES, 08/10/2017).

Eu acredito que ela já tinha esse dom da gestão, [...] ela tinha uma maneira muito peculiar da gestão, que eu acredito até um pouco muito avançado pra época, [...], quando eu entrei no curso de enfermagem e ela era a coordenadora do curso de enfermagem, eu observava que a professora Grasiela ela tinha uma preocupação muito grande, de que nós alunos nos envolvesse de alguma forma, na forma como o curso estava sendo conduzido. (VIEIRA, 16/10/2017).

Observamos que Alves e Vieira consideram a Pioneira como líder nata, pois, na segunda fala, deparamos um tipo de gerenciamento democrático, que escuta o outro e avalia o próprio trabalho, ou seja, à medida que ia exercendo os cargos, aperfeiçoava, concomitantemente, sua prática. Seus conhecimentos de Supervisão e Chefia fizeram dela uma professora- dirigente e diligente - que concedia valor ao relacionamento mais direto entre os professores e alunos, o que fazia ela ser respeitada e admirada como autoridade.

O posicionamento administrativo de Grasiela era permeadopelas competências, dentre elas a de influenciar seus liderados e se fazer modelo. A Pioneira era contra a estagnação profissional, pois, no seu entendimento, o profissional teria que ir em busca de melhorar a prática profissional. Acerca disso, uma das entrevistadas recordou-se de que, "Grasiela se inquietava quando você chegava e dizia que não ia fazer pós-graduação [...], ela sempre estimulava que todo o colegiado tivesse capacitação adequada para o ensino". (VIEIRA, 16/10/2017).

Isso possibilitaria a qualidade da formação docente, e, posteriormente, as virtudes do curso. Ao incentivar a melhoria da formação e do desenvolvimento profissional, estabelecia caminhos para o crescimento da Enfermagem no Ceará. 
[...] ela fez a enfermagem do Ceará crescer, porque na hora que ela capacitou o pessoal, estimulou, e fez um perfil do corpo docente e instalou o mestrado, muitas docentes de outras escolas do estado do Ceará foram se capacitar. (VIEIRA, 16/10/2017).

Desde então, profissionais da Enfermagem do Estado se insertam nos cursos de pós-graduação, desenvolvendo estudos, de modo a ampliar o comprometimento com uma prática social transformadora e dirigida para a melhoria de qualidade de vida, no plano do cuidado individual e coletivo.

\section{Os caminhos trilhados na Pesquisa}

Estudos de Sanna (2007) revelam que pesquisar em Enfermagem tem como objetivo o saber já disponivel e as lacunas desse saber, pois os resultados são novos conhecimentos, que modificam o trabalho dos profissionais de Enfermagem. Na perspectiva de Pedro Demo (2006), a seu turno,

Pesquisar não é somente produzir conhecimento, é sobretudo aprender em sentido criativo. [...] Dialogar com a realidade talvez seja a definição mais apropriada de pesquisa, porque a apanha como princípio científico e educativo faz da pesquisa condição de vida, progresso e cidadania. (P. 44).

A investigação de teor científico, desse modo, tem como função fazer o operário da pesquisa desvelar um conhecimento científico capaz de questionar, investigar, levantar hipóteses, coletar e analisar dados, elaborar propostas, dentre outras competências.

Na obra Vinte e cinco anos: curso de Enfermagem UFC - 1976-2001, Barroso, Silva e Varela (2006) ponderam que, na seara de exame da Enfermagem, os estudiosos defendem o argumento de que a pesquisa é essencial para que a profissão alcance e consolide posição entre as ciências. Logo, compreendemos que a busca ordenada tem relevância no terreno da Enfermagem, e que merece uma atenção maior por parte dos profissionais, com vistas a perfiIhar uma prática fundamentada em princípios científicos.

Ao observamos o Currículo Lattes de Grasiela, percebemos o quanto desenvolveu estudos e pesquisas, em sua maioria, escritos na área da Saúde Pública. As produções são, de um modo geral, livros, capítulos de livros, periódicos e ensaios sob ordenamentos metodológicos. Os dados demonstram o expressivo envolvimento de Grasiela Barroso com a pesquisa científica. São, ao todo, 206 resumos publicados em anais de congressos, 107 artigos em periódicos, 55 capítulos de livros, 16 livros, 15 trabalhos completos publicados em anais de congressos, dentre outros. Grasiela foi pesquisadora de produtividade do Consetho Nacional de Desenvolvimento Científico e Tecnológico - CNPq Nível 1D. Seus projetos de pesquisa eram na área de Educação em Saúde, abordando o tema prevenção a doenças sexualmente transmissiveis (DST), que originou muitos trabalhos.

Os projetos integravam bolsistas de iniciação científica e alunos do mestrado e doutorado, em sua, maioria seus orientandos. Sobre as contribuições deixadas pela Pioneira no âmbito da investigação, uma das entrevistadas evidencia que Grasiela foi uma liderança em pesquisa, pois formava pesquisadores. Seus orientandos seguiram a linha de perquisição deixada pela Professora Grasiela, e continuam a trazer o aporte para a área da Enfermagem, principalmente nos escritos de HIV e AIDS.

[...] o visivel é a materialidade da produção, o número de artigos que ela publicou, o número de livros e capítulos de livros que ela produziu, isso é muito fácil verificar a materialidade nisso, mas o invisivel que é a liderança na pesquisa, a formação de pesquisadores, e o quan- 
to que esses pesquisadores continuam nessa linha de estudo que ela iniciou isso que é mais importante para o pesquisador, é a contribuição da veia da produção de buscar o conhecimento, de produzir o conhecimento, isso ela deixou em todas as pessoas que ela orientou. (VIEIRA, 16/10/2017).

Acerca, ainda, do incentivo à demanda científica, impõe-se destacar a contribuição que a Cientista sob relação trouxe para a formação dos cursos de pós-graduação da UFC em senso lato como em sentido estreito. Após estruturar o curso de graduação, pensando nas melhorias para esse programa e de todos os de que faziam parte, os professores eram motivados à qualificação.

A Professora Grasiela aposentou-se em 1991, no entanto, logo abdicou desse direito, permanecendo na Universidade, retornando às atividades como docente- visitante, renovando o contrato anualmente. E, assim, auxiliou também a implantação dos cursos de Mestrado (1992) e Doutorado (1998). Em 2004, se ausentou, pelo fato de ter sofrido um acidente vascular cerebral. A Professora continuou, entretanto, realizando suas orientações a alunos de pós-graduação. Apesar da idade avançada e malgrado o acidente patológico que a invadiu, estava sempre disposta a fazer algo, pois seu prazer era transmitir o que sabia. Eis que, na madrugada do dia 13 de maio de 2011, Grasiela, aos 85 anos, experimentou o óbito (ALVES et alii., 2016).

\section{Considerações Finais}

Maria Grasiela Teixeira Barroso tornou-se uma das personalidades mais respeitadas no âmbito da história da Enfermagem do Ceará, tendo inclusive reconhecimento na contextura nacional. É considerada a pioneira do ensino em Enfermagem no Estado, havendo contribuído para diversos avanços, tanto para a graduação como para a pós-graduação, o que enriqueceu a valorização do Curso e, consequentemente, a profissão do (a) enfermeiro (a) em geral.

Tendo dedicado meio século de sua vida à Enfermagem, antetantas ações e projetos realizados, o reconhecimento profissional concretizou-se de modos diversificados, pois ela recebeu homenagens em vida e in memoriam, de sorte que as contribuições da Pioneira ultrapassam o tempo e o espaço em que viveu. Grasiela Barroso tinha uma personalidade robusta na liderança, detinha uma concepção clara da profissão e a defendia, lutando por uma nova visão da Enfermagem e de seus profissionais.

Em sua trajetória, percebemos que, ao conhecer a vida de uma pioneira, é possibilitada uma reflexão daquilo que tem a ensinar, bem como um reconhecimento do seu esforço profissional em busca de ver e uma prática expressa nos valores éticos da profissão, e isso não se constitui repentinamente, mas, em cada passo trilhado durante a formação profissional. A esse respeito, Moita (2000) assinala que

Ninguém se forma no vazio. Formar-se supõe troca, experiência, interações sociais, aprendizagens, um sem fim de relações. Ter acesso ao modo como cada pessoa se forma é ter em conta a singularidade da sua história e, sobretudo o modo singular como age, reage e interage com os seus contextos. Um percurso de vida é assim um percurso de formação no sentido em que é um processo de formação. (P. 115).

Os desafios superados, as conquistas e ações realizadas por Grasiela Barroso resultaram para o campo da enfermagem uma visão mais humanística da profissão, favorecendo assim implicações e aprendizados para o cenário contemporâneo como a relevância da qualificação profissional, o exercício a liderança, a proação, o profissionalismo, criticidade e princípios éticos na atuação. Sua participação atuante e sua luta pelo crescimento e qualidade da categoria são exemplos a serem seguidos. 
A jeito de remate, faz-se pertinente enfatizar a relevância de imortalizar a memória de profissionais que deram solidez às bases teóricas e empíricas da profissão da Enfermagem brasileira, preservando e enaltecendo os feitos e ações dessas personalidades (SECAF; COSTA, 2010). O desenvolvimento deste estudo responde ao nosso objetivo, em que demandamos registrar a história de vida de Grasiela Barroso, contribuindo, assim, para preservar e produzir a História da Enfermagem no Estado do Ceará, fechando algumas lacunas com reflexões científicas nesse terreno.

\section{Referências}

ALVES, Maria Dalva Santos et. alii. Grasiela Barroso: Meio Século de Dedicação à Enfermagem Brasileira. In: OGUISSO, Taka; FREITAS, Genival Fernandes de; GONZÁLEZ, José Siles. Enfermagem: História, Cultura dos cuidados e Métodos. Rio de Janeiro: Águia Dourada, 2016. pp. 87-100.

BARREIRA, leda de Alencar. Memória e história para uma nova visão da enfermagem no Brasil. Revista Latino-Americana de Enfermagem, Ribeirão Preto, Escola de Enfermagem de Ribeirão Preto - USP, v. 7, n. 3, pp. 87-93, jul./1999. Disponivel em: http:// www.scielo.br/pdf/rlae/v7n3/13480.pdf. Acessado em 11/09/2019.

BARROSO, Maria Grasiela Teixeira; COSTA, Lígia Barros; VARELA, Zulene Maria de Vasconcelos. Dez anos Curso de Enfermagem UFC 1976-1986. Fortaleza: Editora UFC, 1992.

BARROSO, Maria Grasiela Teixeira; SILVA, Raimunda Magalhães; VARELA, Zulene Maria de Vasconcelos. Vinte e cinco anos Curso de Enfermagem. Fortaleza: Editora UFC, 2006.

BORGES, Vavy Pacheco. Grandezas e misérias da biografia. In: PINSKY, Carla Bassanezi (Org.). Fontes Históricas. São Paulo: Contexto, 2014. pp. 203-233.

DEMO, Pedro. Pesquisa: princípio científico e educativo. São Paulo: Cortez, 2006.

ESCÁRIO, Silvana. Concepção humanista (Carl Ro- gers): como recurso de atuação na educação para o trânsito - aprendizagem contextualizada. Revista @rquivo Brasileiro de Educação, Belo Horizonte, v. 2, n. 3, pp. 83-95, jan./jun, 2014. Disponivel: http:// periodicos.pucminas.br/index.php/arquivobrasileiroeducacao/article/view/P.2318-7344.2014v2n3p83. Acessado em 11/09/2019

ESQUINSANI, Rosimar Serena Siqueira. Entre percursos, fontes e sujeitos: pesquisa em educação e uso da história oral. Educação e pesquisa, São Paulo, Universidade de São Paulo, v. 38, n. 1, pp. 217-228, 2012. Disponivel em: http:/ / www.revistas.usp.br/ep/ article/view/28335/30193. Acessado em 05/09/2019.

FERREIRA, Marieta de Moraes; AMADO, Janaína (Org.). Usos e Abusos da história oral. Rio de Janeiro: Editora FGV, 2006.

FREIRE, Lidiane Dias. Grasiela - um marco nos 25 anos do curso de Enfermagem da FFOE - UFC. Revista RENE, Fortaleza, Universidade Federal do Ceará, v. 3, n. 1, pp. 97-103, jan./jun. 2002. Disponível em: http://periodicos.ufc.br/rene/article/ view/5755/4107. Acessado em 24/09/2019.

FREITAS, Marcos Cezar de; BICCAS, Maurilane de Souza. História social da educação no Brasil (19261996). São Paulo: Cortez, 2009.

MEIHY, José Carlos Sebe Bom; HOLANDA, Fabíola. História Oral: como fazer, como pensar. São Paulo: Contexto, 2013.

MENDES, Emanoela Therezinha Bessa. A Formação da Enfermeira Cearense e a Escola São Vicente de Paulo (1943-1977). [Mestrado em Educação- Dissertação] Programa de Pós-Graduação em Educação, Universidade Estadual do Ceará, Fortaleza, 2013.

MIRANDA, Karla Corrêa Lima, BARROSO, Maria Grasiela Teixeira. A contribuição de Paulo Freire à prática e educação crítica em Enfermagem. Revista Latino-Americana de Enfermagem, Ribeirão Preto, Escola de Enfermagem de Ribeirão Preto - USP, v. 12, n. 4, pp. 631-635, jul./ago. 2004. Disponivel em: http://www.scielo.br/pdf/rlae/v12n4/v12n4a08. pdf. Acessado em: 24 set. 2019.

MOITA, Maria da Conceição. Percursos de formação e de trans-formação. In: NÓVOA, Antônio. Vida de 
Professores. Porto: Porto Editora, 2000. p. 111-140.

OLIVEIRA, Marinalva de Jesus et. alii. História Oral e o Método Biográfico: Congruências, Diferenças e Potencialidades de Utilização no Campo da Administração. In: Encontro em Ensino e Pesquisa em Administração e Contabilidade - ENEPQ, IV, 2013, Brasília. Anais. Brasília, 2013.

PADILHA, Maria Itayra; NELSON, Sioban; BORENSTEIN, Miriam Sussekind. As biografias como um dos caminhos na construção da identidade do profissional da enfermagem. História, Ciências, Saúde - Manguinhos, Rio de Janeiro, v. 18, supl.1, pp. 241-252, dez. 2011. Disponivel em: http:// www.scielo.br/scielo.php?script=sci_arttext\&pi$d=$ S0104-59702011000500013 Acessado em: 24 set. 2019.

SANNA, Maria Cristina. Os processos de trabalho em Enfermagem. Revista Brasileira de Enfermagem, Brasília, v. 60, n. 2, pp. 221-224, abr./2007. Disponível em: http://www.scielo.br/pdf/reben/v60n2/ a17v60n2.pdf Acessado em: 24 set. 2019.

Biografia. In: OGUISSO, Taka; CAMPOS, Paulo Fernando de Souza; FREITAS, Genival Fernandes de. Pesquisa em História da Enfermagem. Barueri: Manole, 2011. pp. 301-338.

SECAF, Victoria; COSTA, Hebe C. Boa-Viagem A. Enfermeiras do Brasil: história das pioneiras. São Paulo: Martinari, 2007.

SOUSA, Leilane Barbosa de Sousa, BARROSO, Maria Grasiela Teixeira. Reflexão sobre o cuidado como essência da liderança em Enfermagem. Escola Anna Nery Revista de Enfermagem, Rio de Janeiro, Universidade Federal do Rio de Janeiro, v. 13, n. 1, pp. 181-187 jan./mar. 2009. Disponivel em: http:/ /eean. edu.br/detalhe_artigo.asp?id=414 Acessado em: 24 set. 2019.

Recebido em: 18.10.2019 Revisado em: 25.03.2020 Aprovado em: 29.03 .2020

Mariza da Costa Pereira é Mestranda em Educação do Programa de Pós-Graduação em Educação da Universidade Estadual do Ceará. Participa do Grupo de Pesquisa Educação, História e Saúde Coletiva (GPEHSC). E-mail: marizadacosta16@ gmail.com

Silvia Maria Nóbrega-Therrien é Doutora em Sociologia da Educação. Professora do Programa de Pós-Graduação em Educação da Universidade Estadual do Ceará. Coordenadora do Grupo de Pesquisa Educação, História e Saúde Coletiva (GPEHSC). E-mail: silnth@terra.com.br

Andréa da Costa Silva é Pedagoga. Mestre em Educação. Doutoranda em Educação do Programa de Pós-Graduação em Educação da Universidade Estadual do Ceará. Colaboradora no Grupo de Pesquisa Educação, História e Saúde Coletiva (GPEHSC). E-mail: andreacosta_silva@yahoo.com.br 